This item was submitted to Loughborough's Research Repository by the author.

Items in Figshare are protected by copyright, with all rights reserved, unless otherwise indicated.

\title{
Heightened exercise-induced oxidative stress at simulated moderate level altitude vs. sea level in trained cyclists
}

PLEASE CITE THE PUBLISHED VERSION

https://doi.org/10.1123/ijsnem.2015-0345

\section{PUBLISHER}

(c) Human Kinetics, Inc.

\section{VERSION}

AM (Accepted Manuscript)

\section{PUBLISHER STATEMENT}

This work is made available according to the conditions of the Creative Commons Attribution-NonCommercialNoDerivatives 4.0 International (CC BY-NC-ND 4.0) licence. Full details of this licence are available at: https://creativecommons.org/licenses/by-nc-nd/4.0/

\section{LICENCE}

CC BY-NC-ND 4.0

\section{REPOSITORY RECORD}

Wadley, Alexander J., Ida S. Svendsen, and Michael Gleeson. 2019. "Heightened Exercise-induced Oxidative Stress at Simulated Moderate Level Altitude Vs. Sea Level in Trained Cyclists". figshare. https://hdl.handle.net/2134/32796. 


\title{
Heightened Exercise-Induced Oxidative Stress at Simulated Moderate Level Altitude vs. Sea Level in Trained Cyclists
}

\author{
Alex, J. Wadley, Ida, S. Svendsen, and Michael Gleeson
}

\begin{abstract}
Altitude exposure can exaggerate the transient increase in markers of oxidative stress observed following acute exercise. However, these responses have not been monitored in endurance-trained cyclists at altitudes typically experienced while training. Endurance trained males $\left(n=12\right.$; mean $( \pm S D)$ age: $28 \pm 4$ years, $\left.\dot{V} \mathrm{O}_{2 \max } 63.7 \pm 5.3 \mathrm{ml} / \mathrm{kg} / \mathrm{min}\right)$ undertook two 75 min exercise trials at $70 \%$ relative $\dot{V} \mathrm{O}_{2 \max }$; once in normoxia and once in hypobaric hypoxia, equivalent to $2000 \mathrm{~m}$ above sea level (hypoxia). Blood samples were collected before, immediately after and $2 \mathrm{~h}$ postexercise to assess plasma parameters of oxidative stress (protein carbonylation (PC), thiobarbituric acid reactive substances (TBARS), total antioxidant capacity (TAC) and catalase activity (CAT)). Participants cycled at $10.5 \%$ lower power output in hypoxia vs. normoxia, with no differences in heart rate, blood lactate or rating of perceived exertion observed. PC increased and decreased immediately after exercise in hypoxia and normoxia respectively (nmol/mg/protein: Normoxia $-0.3 \pm 0.1$, Hypoxia $+0.4 \pm 0.1$; both $p<.05$ ). CAT increased immediately postexercise in both trials, with the magnitude of change greater in hypoxia $(\mathrm{nmol} / \mathrm{min} / \mathrm{ml}$ : Normoxia $+12.0 \pm 5.0$, Hypoxia $+27.7 \pm 4.8$; both $p<.05$ ). CAT was elevated above baseline values at $2 \mathrm{~h}$ postexercise in Hypoxia only (Normoxia $+0.2 \pm 2.4$, Hypoxia $+18.4 \pm 5.2 ; p<.05$ ). No differences were observed in the changes in TBARS and TAC between hypoxia and normoxia. Trained male cyclists demonstrated a differential pattern/ timecourse of changes in markers of oxidative stress following submaximal exercise under hypoxic vs. normoxic conditions.
\end{abstract}

Keywords: exercise, protein carbonyl, redox, antioxidant, hypoxia

It has been established that exposure to hypoxic conditions at altitude $(>1800 \mathrm{~m})$ can elicit perturbations in redox homeostasis (Dosek et al., 2007; Møller et al., 2001; Radak et al., 2014). Despite lower partial oxygen pressures at altitude, an exaggerated rate of reactive oxygen and nitrogen species (RONS) production is known to be coupled with weakened enzymatic and nonenzymatic antioxidants systems, eliciting increased oxidative stress. For example, previous investigations in humans have observed elevated blood biomarkers of oxidative stress (e.g., lipid peroxidation (Siervo et al., 2014; Taylor et al., 2010)) and a decline in reduced: oxidized glutathione ratio (Joanny et al., 2001; Taylor et al., 2010) at rest, relative to measures at sea level.

A single bout of exercise of adequate intensity and duration can increase the production of RONS (McArdle, 2005). Exercise-induced RONS are involved in intricate redox signaling pathways implicated with the adaptive response to exercise (Cobley et al., 2015; Gomez-Cabrera et al., 2008; Ristow et al., 2009); however their production can also elicit acute oxidative stress (Fisher-Wellman \& Bloomer, 2009; Wadley et al., 2015a, 2015b) that may lead to muscle fatigue and decrements in physical workload. Exercise-induced oxidative stress is commonly measured by monitoring oxidation of biomolecules and/or antioxidant capacity in plasma; collectively termed biomarkers of oxidative stress (Fisher-Wellman et al., 2009; Wadley, 2015). Many field-based studies suggest that acute exercise in hypoxia leads to an exaggerated increase in biomarkers of oxidative stress relative to sea level (Joanny et al., 2001; Krzeszowiak J, Zawadzki M, Markiewicz-Górka I, Kawalec A, 2014; Miller et al., 2013; Morales-Alamo et al., 2012; Wozniak et al., 2001). A recent study by McGinnis and colleagues (McGinnis et al., 2014) investigated the independent effects of altitude exposure and acute exercise on markers of oxidative stress by simulating altitude in an environmental chamber. Under strictly controlled experimental conditions, cycling at $60 \%$ altitude specific $\mathrm{VO}_{2 \text { peak }}$ at $3000 \mathrm{~m}$ caused a greater increase in postexercise lipid hydroperoxides than cycling at $60 \%$

The authors are with the School of Sport, Exercise \& Health Sciences, Loughborough University, Leicestershire, UK. Address author correspondence to Alex Wadley at a.wadley@worc.ac.uk. 
normoxic specific $\mathrm{VO}_{2 \text { peak }}$ at $975 \mathrm{~m}$. This novel approach highlighted the independent affect that hypoxia can have on postexercise oxidative stress, at the same physiological stress as equivalent normoxic exercise (i.e., lower absolute power output in the hypoxic trial, but no differences in heart rate or percentage altitude-specific maximal oxygen consumption). The authors suggested the need for further studies in this area, using higher exercise intensities and comparing different altitude exposures.

Endurance athletes periodically undertake training camps at moderate altitudes of around 1800-2500 $\mathrm{m}$ above sea level. There is evidence that the ascent (Møller et al., 2001; Siervo et al., 2014; Taylor et al., 2012) and descent (González et al., 2005) to and from altitude can increase basal markers of oxidative stress, with regular exercise under these conditions known to cause a reduction (Debevec et al., 2014). Interestingly, there is evidence that individuals who are acclimatized to altitude demonstrate an exaggerated increase in markers of oxidative stress compared with nonacclimatized individuals following both groups cycling at $4500 \mathrm{~m}$ (Sinha et al., 2010). This is despite the short-term (i.e., 4 weeks for the duration of the study) exposure to altitude increasing resting biomarkers of oxidative stress in the nonacclimatized group. An understanding of the impact of altitude exposure on exercise-induced oxidative stress is therefore an important consideration for endurance athletes. Many of the studies in the literature investigating acute hypoxic exercise have not reported whether participants have been previously exposed to altitude or not, a factor that appears to markedly influence acute redox responses following exercise. Translation of previous studies conducted at high altitude (3000 $\mathrm{m}$ above sea level) (Joanny et al., 2001; Siervo et al., 2014; Sinha et al., 2009; Vij et al., 2005) is therefore difficult, given that competitive athletes are typically not exposed to elevations above $2500 \mathrm{~m}$. Furthermore, because $\dot{V} \mathrm{O}_{2 \max }$ is reduced at altitude (Ferretti et al., 1997), cycling at the same absolute power output in hypoxia will result in

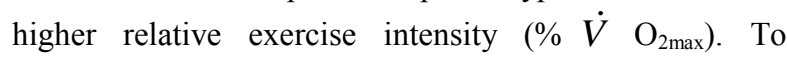
determine whether differences in responses are due to hypoxia per se, rather than an increase in relative exercise intensity, trials can be instead matched based on a fraction of altitude-specific $\dot{V} \mathrm{O}_{2 \max }$. This is also of greater relevance to endurance athletes, given that they typically train and compete at similar relative exercise intensities at altitude and at sea level. Accordingly, the aim of present study was to compare changes in plasma biomarkers of oxidative stress in endurance-trained cyclists exercising at the same relative intensity in normoxia compared with hypobaric hypoxia, equivalent to $2000 \mathrm{~m}$ above sea level.

\section{Methods}

\section{Participants}

Twelve healthy, male cyclists (Table 1) gave their informed and written consent to take part in the study, which was approved by the regional ethics committee of southern Norway. Before the start of the study, participants completed a health-screening questionnaire. Participants were included if they were between 18 and 40 years of age and were currently healthy and with no symptoms of upper respiratory tract infection in the previous two weeks. All participants were engaged in regular endurance training $(\geq$ three times per week) and had not been exposed to natural or simulated altitude (equivalent to $\geq 1,000 \mathrm{~m}$ above sea level) for at least 4 months. Furthermore, participants had not engaged in any structured altitude training for one year. Participants were excluded if they were smokers, had taken any medication during the past four weeks or were suffering from/ had a history of cardiac, hepatic, pulmonary, renal, neurological, hematological, psychiatric, or gastrointestinal illness.

$$
k<<<<\text { INSERT TABLE } 1 \text { ABOUT HERE }>>>\mid
$$

\section{Laboratory Visits}

\section{Maximal Oxygen Consumption}

On the first laboratory visit, 1-2 weeks before the first experimental trial, an incremental cycle test to exhaustion was used for determination of $\dot{V} O_{2}{ }_{\text {MAx. On an }}$ electronically braked ergometer (Lode Excalibur Sport, Groningen, Netherlands), participants began cycling at 60 $\mathrm{W}$, with increments of $35 \mathrm{~W}$ every 3 -min interval thereafter until exhaustion. Rating of perceived exertion (RPE) was noted and heart rate measured continuously using shortrange telemetry (Polar, Kempele, Finland). Expired gas was collected and analyzed (Oxycon Pro, Erich Jaeger $\mathrm{GmbH}$, Hoechberg, Germany) to calculate a work rate corresponding to $70 \% \dot{V} \mathrm{O}_{2}$ MAx for the two subsequent trials. The same relative workload for the hypoxic trial was calculated using a linear equation based on the results of a pilot study in the recompression chamber showing that $\dot{V}$ $\mathrm{O}_{2 \max }$ decreases by, on average, $10.4 \%$ in hypobaric hypoxia equivalent to $2000 \mathrm{~m}$ above sea level (unpublished data).

\section{Experimental Trials}

One to two weeks after the first visit, participants returned to the laboratory following an overnight fast to undertake one of two randomized exercise trials, each separated by at least one week. Participants abstained from caffeine, alcohol and strenuous exercise for at least $24 \mathrm{hr}$ A rested venous blood sample (PRE) was obtained by venepuncture from an antecubital vein before entry into a recompression chamber (Norsk undervannsteknikk A/S, Haugesund, Norway). For both trials, participants completed a standardized 10 -min warm-up at $55 \%$ relative $\dot{V} \mathrm{O}_{2 \max }$, followed by $75 \mathrm{~min}$ at $70 \%$ relative $\dot{V} \mathrm{O}_{2 \max }$, on an electromagnetically braked cycle ergometer (Lode Excalibur Sport, Groningen, Netherlands). Following the exercise trials, participants remained inside the recompression chamber for a 2-hr resting recovery. During the normoxic trial, the recompression chamber was switched off, and the doors remained open. During the hypoxic trial (exercise and recovery), the pressure was 
adjusted to $800 \mathrm{mbar}$ (equivalent to $2000 \mathrm{~m}$ above sea level at $17{ }^{\circ} \mathrm{C}$ ). These conditions have previously been shown to elicit a $5 \%$ reduction in oxygen saturation (Bendz et al., 2000). Carbon dioxide levels were maintained via thee $\mathrm{CO}_{2}$ scrubbers containing soda lime, and oxygen was supplied continuously at a rate equal to oxygen consumption to preserve normal ambient composition $\left(\sim 20.9 \% \mathrm{O}_{2}, \sim 0.04 \%\right.$ $\mathrm{CO}_{2}$ ). To confirm that the same relative exercise was achieved in both trials, heart rate was measured continuously via short range telemetry (RCX3, Polar, Kempele, Finland), RPE was recorded every $10 \mathrm{~min}$, and blood lactate concentration was measured from a finger prick blood sample using a portable blood lactate analyzer (Lactate Pro LT-1710, Arkray, Kyoto, Japan) every 20 min during exercise. Additional blood samples were taken immediately after cessation of exercise (POST), and after the 2 -hr recovery period ( $2 \mathrm{~h}$ POST). All blood (PRE, POST and $2 \mathrm{~h}-\mathrm{POST}$ ) was collected into vacutainer tubes (Becton Dickinson, Oxford, UK) containing $\mathrm{K}_{3}$ EDTA as an anticoagulant. Blood was centrifuged at $1500 \mathrm{~g}$ for $10 \mathrm{~min}$ at $4{ }^{\circ} \mathrm{C}$. Plasma was then extracted and stored at $-80^{\circ} \mathrm{C}$ until further analysis.

\section{Analytical Measures}

Total Antioxidant Capacity.

Plasma TAC was assessed using the Ferric Reducing Ability of Plasma (FRAP) assay originally developed by Benzie et al. (Benzie \& Strain, 1996). Final concentrations were read at $650 \mathrm{~nm}$ (Varioskan Flash, Thermo Fisher Scientific, Leicestershire, UK) and TAC determined using absorbance values of known ascorbic acid concentrations $(0-2000 \mu \mathrm{M})$. Values were expressed as $\mu \mathrm{M}$ of antioxidant power relative to ascorbic acid.

\section{Thiobarbituric acid Reactive Substances.}

TBARS was assessed using an adapted version of the protocol reported by Kasielski and Nowak (Kasielski, 2001). Absorbance values were read at 532nm, with correction wavelengths run at $572 \mathrm{~nm}$ (sialic acid) and 540 $\mathrm{nm}$ (hemoglobin) (Devasagayam, 2003). Sample TBARS concentration was determined by comparing absorbance values with known Tetramethoxypropane concentrations (0-50 $\mu \mathrm{M})$.

\section{Protein Carbonylation.}

PC was assessed by ELISA (Buss et al., 1997; Carty et al., 2000). Samples and standards were diluted in coating buffer $(50 \mathrm{mM}$ sodium carbonate, $\mathrm{pH}=9.2)$ to $\mathrm{a}$ concentration of $0.05 \mathrm{mg} / \mathrm{ml}$ using the bicinchoninic assay method (Smith et al., 1985). Plasma protein carbonyls were derivatized with 2, 4-dinitrophenylhydrazine (DNPH: $1 \mathrm{mM}$, in $2 \mathrm{M} \mathrm{HCl}$ ) and incubated with monoclonal mouse anti-DNP antibody (Sigma Aldrich, Dorset, UK) and rat antimouse IgE, conjugated to HRP (AbD Serotec, Kidlington, Oxfordshire). Well absorbance was measured at $490 \mathrm{~nm}$ and the PC content determined by using absorbance values of known PC standards made in our laboratory (1.28-5.20 nmol/mg protein).
Catalase Activity.

The peroxidatic activity of Catalase was measured in plasma using a commercially available assay kit, according to the manufacturer's instructions (Cayman Chemical, Cambridge, UK). Final absorbance values were measured at $540 \mathrm{~nm}$ and compared with values of known formaldehyde concentration $(0-75 \mu \mathrm{M})$. One unit catalase activity was defined as the amount of enzyme that caused the formation of $1.0 \mathrm{nmol}$ of formaldehyde per minute at $25{ }^{\circ} \mathrm{C}$.

Data Reduction and Statistical Analysis.

All results are presented as mean $\pm S E$ unless otherwise stated. Statistical calculations and analyses were performed using SPSS (PASW Statistics, 22.0). Shapiro-Wilk tests were used to investigate normal distribution and differences between variables at baseline were assessed using one-way analyses of variance (ANOVA). Repeated Measures Analysis of Variance (ANOVA) tests were used to contrast changes over time (PRE, POST and $2 \mathrm{hr}-\mathrm{POST}$ ), and between the two exercise trials (Normoxia and Hypoxia) for each marker of oxidative stress (PC, TBARS, CAT, and TAC). Post hoc pairwise comparisons were made with Bonferroni adjustments for multiple comparisons. Other physiological parameters (i.e., average workload, lactate, RPE and heart rate during exercise) were assessed by paired samples T-tests. Statistical significance was accepted at the $p<.05$ level.

\section{Results}

\section{Physiological Responses to Exercise}

On average, participants cycled at $10.5 \%$ lower power output in Hypoxia compared with Normoxia (Figure 1; $p<$ .0001). There were no significant differences in heart rate, blood lactate concentration or RPE between conditions (Table 2).

\section{$k<<<$ INSERT FIGURE 1 ABOUT HERE AND TABLE 2 ABOUT HERE $>>>1$}

\section{Biochemical Parameters of Oxidative Stress}

Exercise-induced changes in PC, TBARS, TAC and CAT under hypoxic and normoxic conditions are reported in Figure $2(\mathrm{~A}+\mathrm{B})$ and Figure $3(\mathrm{~A}+\mathrm{B})$. No differences in baseline values were noted. Exercise caused an increase in TAC $(p=.013)$ and CAT $(p=.002)$ POST in both conditions (time effects, TAC: $\mathrm{F}_{2,22}=7.4, p=.003$; CAT: $\left.\mathrm{F}_{2,22}=14.5, p<.0001\right)$, with CAT still significantly greater than PRE at $2 \mathrm{hr}$ POST in hypoxia only $(p=.014)$. The magnitude of change in CAT POST $(p=.018)$ and $2 \mathrm{hr}$ $\operatorname{POST}(p=.010)$ was greater in hypoxia compared with normoxia (Time $\times$ Condition interaction effect: $F_{2,22}=6.0$, $p=.008)$. No changes in TBARS concentration were noted in either condition $(p>.05)$. A differential response was noted for PC values following exercise in hypoxia and normoxia (Time $\times$ Condition interaction effect: $F_{2,22}=9.0$, $p=.001)$. PC content significantly declined POST under normoxic conditions $(p=.016)$, whereas it increased under hypoxic conditions (PRE to POST: $p=.033$; hypoxia vs. 
normoxia: $p=.018$ ), relative to PRE. PC content was not different between hypoxic and normoxic conditions at $2 \mathrm{hr}$ POST $(p=.249)$, but PC did significantly decline relative to POST in hypoxia only $(p=.030)$.

k $<<<<<$ INSERT FIGURE 2 AND FIGURE 3 ABOUT HERE $>>>1$

\section{Discussion}

The aim of the current study was to evaluate the independent effects of acute exercise and hypoxic exposure on markers of oxidative stress in trained male cyclists. Importantly, we examined these acute changes at sea level and at conditions simulating $2000 \mathrm{~m}$ above sea level, which accurately reflects the training habits of competitive endurance athletes. Exercise at $2000 \mathrm{~m}$ above sea level caused a greater increase in plasma CAT activity and PC content than exercise at sea level, even when exercise was performed at the same relative exercise intensity (i.e., equal physiological exertion). However, no differences were observed in plasma TAC or TBARS concentration between the two conditions.

Many of the studies assessing oxidative stress and exercise under hypoxic conditions have examined the effects of high altitude (i.e., $\geq 3000 \mathrm{~m}$ ) in field-based studies, with prior exposure of the participants commonly not reported (Joanny et al., 2001; Miller et al., 2013; Sanchari et al., 2010; Sinha et al., 2009). At rest, the ascent (Møller et al., 2001; Siervo et al., 2014; Taylor et al., 2012) and descent (González et al., 2005) from altitude has been shown to cause marked increases in lipid peroxidation. The participants in the current study had not been exposed to altitude for at least 4 months, minimizing the impact of prior exposure perturbing basal or exercise-induced redox state, which has previously been demonstrated in active individuals (Sanchari et al., 2010; Sinha et al., 2009). Our findings show that only selective biomarkers of oxidative stress were exaggerated following exercise under hypoxic conditions relative to normoxia. Specifically, increases in PC content were greater immediately postexercise, with CAT activity greater both immediately and at $2 \mathrm{hr}$ postexercise. Interestingly, PC content decreased relative to baseline immediately following exercise in normoxia. It has recently been suggested that exercise of varying intensities may stimulate the clearance of PC groups present at rest, while the simultaneous production of RONS from increased metabolic activity during exercise causes an increase in PC groups (Wadley, 2015[AUQ1]). The mechanisms governing PC clearance are unclear; however the present data suggest that exercise under hypoxic conditions drives a net increase plasma PC content that is not observed when equivalent exercise was undertaken at sea level.

We observed no differences in plasma TBARS or TAC levels between the normoxic and hypoxic exercise trials. Using a similar experimental design, McGinnis et al. (McGinnis et al., 2014), reported a greater increase in postexercise lipid hydroperoxide concentration, but no differences in PC content or TAC level 2-hr following hypoxic exercise $(60 \mathrm{~min}$ at $60 \%$ altitude specific $\dot{V}$ $\left.\mathrm{O}_{2 \max }\right)$. These findings confirm that nonenzymatic antioxidants are not mobilized to a greater extent following exercise under hypoxic conditions at this range of relative intensities $\left(60-70 \% \dot{V} \mathrm{O}_{2 \max }\right)$. Interestingly, some studies have indicated a supressed antioxidant response in the recovery period from exercise at altitude; however these changes have been reported at much higher altitudes (Ballmann et al., 2014; Peters et al., 2015). Exaggerated increases in markers of lipid peroxidation have been highlighted in field-based studies comparing exercise at altitude and sea level (Joanny et al., 2001; Wozniak et al., 2001). The laboratory based protocols used in the McGinnis study and our study were designed to elicit similar physiological responses in both trials. This novel approach controlled for the reduction in maximal oxygen uptake observed at altitude, allowing for the independent assessment of exercise and hypoxia on parameters of postexercise metabolism. The protocol used in the current study was more intense and prolonged than the study by McGinnis (McGinnis et al., 2014), a factor that would presumably exaggerate RONS production and thus markers of oxidative stress, such as TBARS. Indeed, protein carbonyl content did not increase, but declined in both the normoxic and hypoxic trials of the McGinnis study. Discrepancies in the lipid peroxidation findings are therefore likely attributable to differences in the specific lipid biomarker of oxidative stress analyzed or other aspects of study design. For example, the participants in the current study had a higher aerobic capacity (mean $\mathrm{VO}_{2 \max }$ $63.7 \mathrm{ml} / \mathrm{kg}$ vs. $51.7 \mathrm{ml} / \mathrm{kg}$ ), a factor that would likely promote elevated tissue antioxidant enzyme content (Gomez-Cabrera et al., 2008; Khassaf et al., 2001, 2003). A combination of these factors may explain why smaller increases in plasma lipid hydroperoxide concentration have been documented following exercise conditions simulating lower partial oxygen pressures in individuals with higher aerobic fitness (Wilber et al., 2004).

The results of this study suggest that protein oxidation, but not lipid peroxidation is elevated to a greater degree following submaximal exercise in hypoxic conditions. The prolonged increase in catalase activity observed might be a response to elevated protein oxidation, given that nonenzymatic antioxidants were not mobilized to a greater extent relative to the normoxic trial. RONS have a broad range of functions in postexercise metabolic adaption, and thus interpreting the significance of elevated plasma PC groups immediately following exercise under hypoxic conditions is challenging. The increase in plasma PC formation is likely the result of increased oxidation of albumin, the most abundant plasma protein (Quindry et al., 2015), and may therefore be considered a reflection of altered systemic redox balance. PC content was normalized (i.e., increase in the normoxia and decrease in the hypoxia trial) $2 \mathrm{hr}$ postexercise in both trials and it is conceivable that metabolic signaling events may have been altered within this timeframe as a result of the differential postexercise oxidative stress responses. This has been 
highlighted as an area for future investigation in a recent review (Quindry et al., 2015).

This study is not without limitations. The strict experimental laboratory conditions implemented using the environmental chamber allowed for control of various physiological parameters. However, we cannot dismiss the impact of other environmental differences, such as UV light (Radak et al., 2014), that might increase oxidative stress upon ascent to high natural altitudes.

\section{Conclusions}

The present data show that only selective markers of oxidative stress are elevated to a greater extent in endurance trained participants exercising under conditions simulating training level altitude, relative to sea level. Future studies are required to elucidate the significance of elevated postexercise protein carbonyl content and catalase activity in athletes regularly training at altitude.

\section{Acknowledgments}

Professor Michael Gleeson and Ida Svendsen were involved in the conception and design of the investigation. This study formed part of a larger investigation that assessed parameters of systemic and mucosal immunity (Svendsen et al., in review). Changes in exercise-induced oxidative stress were retrospective analyses proposed by Dr Alex Wadley. Ida Svendsen carried out all data collection. Dr Alex Wadley performed all laboratory and statistical analysis. Drafting of the article was by Dr Alex Wadley and all authors carried out editing of the final version.

\section{Conflict of Interest}

None of the authors declare a conflict of interest.

\section{References}

Ballmann, C., McGinnis, G., Peters, B., Slivka, D., Cuddy, J., Hailes, W., . . . Quindry, J. (2014). Exerciseinduced oxidative stress and hypoxic exercise recovery. European Journal of Applied Physiology, 114, 725-733. PubMed doi:10.1007/s00421-013-2806-5

Bendz, B., Rostrup, M., Sevre, K., \& Andersen, T.O. (1657-1658). S. P. (2000). Association between acute hypobaric hypoxia and activation of coagulation in human beings. Lancet, 356(9242).

Benzie, I.F., \& Strain, J.J. (1996). The ferric reducing ability of plasma (FRAP) as a measure of "antioxidant power": the FRAP assay. Analytical Biochemistry, 239(1), 70-76 Retrieved from http://www.ncbi.nlm.nih.gov/pubmed/8660627. PubMed doi:10.1006/abio.1996.0292

Buss, H., Chan, T. P., Sluis, K. B., Domigan, N. M., \& Winterbourn, C. C. (1997). Protein carbonyl measurement by a sensitive ELISA method. Free Radical Biology and Medicine, 23(3), 361-366. Retrieved from $<$ Go to ISI $>$ ://A1997XG67400002

Carty, J.L., Bevan, R., Waller, H., Mistry, N., Cooke, M., Lunec, J., \& Griffiths, H.R. (2000). The effects of vitamin $\mathrm{C}$ supplementation on protein oxidation in healthy volunteers. Biochemical and Biophysical Research Communications, 273(2),
$729-735$

Retrieved

from

http://www.ncbi.nlm.nih.gov/pubmed/10873672.

PubMed doi:10.1006/bbrc.2000.3014

Cobley, J.N., McHardy, H., Morton, J.P., Nikolaidis, M.G., \& Close, G.L. (2015). Influence of vitamin C and vitamin $\mathrm{E}$ on redox signalling: Implications for exercise adaptations. Free Radical Biology \& Medicine. doi:10.1016/j.freeradbiomed.2015.03.018

Debevec, T., Pialoux, V., Mekjavic, I.B., Eiken, O., Mury, P., \& Millet, G.P. (2014). Moderate exercise blunts oxidative stress induced by normobaric hypoxic confinement. Medicine and Science in Sports and Exercise, 46(1), 33-41. PubMed doi:10.1249/MSS.0b013e31829f87ef

Devasagayam, T. P. a, Boloor, K. K., \& Ramasarma, T. (2003). Methods for estimating lipid peroxidation: An analysis of merits and demerits. Indian Journal of Biochemistry \& Biophysics, 40(5), 300-308. PubMed

Dosek, A., Ohno, H., Acsa, Z., Taylor, A.W., \& Radak, Z. (2007). High altitude and oxidative stress. Respiratory Physiology \& Neurobiology, 30(2-3), 128-131. doi:10.1016/j.resp.2007.03.013

Ferretti, G., Moia, C., Thomet, J.M., \& Kayser, B. (1997). The decrease of maximal oxygen consumption during hypoxia in man: a mirror image of the oxygen equilibrium curve. The Journal of Physiology, 498(1), 231-237. PubMed doi:10.1113/jphysiol.1997.sp021854

Fisher-Wellman, K., \& Bloomer, R.J. (2009). Acute exercise and oxidative stress: a 30 year history. Dynamic Medicine, 8, 1-25. PubMed doi:10.1186/1476-5918-8-1

Gomez-Cabrera, M.C., Domenech, E., Romagnoli, M., Arduini, A., Borras, C., \& Pallardo, F.V. ... Viña, J. (2008). Oral administration of vitamin $C$ decreases muscle mitochondrial biogenesis and hampers training-induced adaptations in endurance performance. The American Journal of Clinical Nutrition, $\quad 87(1), \quad 142-9 . \quad$ Retrieved from http://www.ncbi.nlm.nih.gov/pubmed/18175748

González, G., Celedón, G., Escobar, M., Carlos Sotomayor, V. F., Benítez, D., \& Behn, C. (2005). Red Cell Membrane Lipid Changes at $3500 \mathrm{~m}$ and on Return to Sea Level. High Altitude Medicine \& Biology. Winter, 6(4), 320-326.

Joanny, P., Steinberg, J., Robach, P., Richalet, J.P., Gortane, C., Gardette, B., \& Jammes, Y. (2001). Operation Everest III (Comex'97): the effect of simulated severe hypobaric hypoxia on lipid peroxidation and antioxidant defence systems in human blood at rest and after maximal exercise. Resuscitation, 49(3), 307-314. PubMed doi:10.1016/S0300-9572(00)00373-7

Kasielski, M., \& Nowak, D. (2001). Long-term administration of $\mathrm{N}$-acetylcysteine decreases hydrogen peroxide exhalation in subjects with chronic obstructive pulmonary disease. Respiratory Medicine, 95(6), 448-456. PubMed doi:10.1053/rmed.2001.1066 
Khassaf, M., Child, R.B., McArdle, A., Brodie, D.A., Esanu, C., \& Jackson, M.J. (2001). Time course of responses of human skeletal muscle to oxidative stress induced by nondamaging exercise. Journal of Applied Physiology (Bethesda, Md.), 90(3), 1031-1035 Retrieved from http://www.ncbi.nlm.nih.gov/pubmed/11181616. PubMed

Khassaf, M., McArdle, A., Esanu, C., Vasillaki, A., McArdle, F., Griffiths, R., . . . Jackson, M. (2003). Effect of vitamin $\mathrm{C}$ supplements on antioxidant defence and stress proteins in human lymphocytes and skeletal muscle. The Journal of Physiology, 549(2), 645-652. PubMed doi:10.1113/jphysiol.2003.040303

Krzeszowiak, J., Zawadzki, M., Markiewicz-Górka, I., \& Kawalec, A.P.K. (2014). The influence of 9-day trekking in the Alps on the level of oxidative stress parameters and blood parameters in native lowlanders. Annals of Agricultural and Environmental Medicine, 21(3), 585-589. PubMed doi:10.5604/12321966.1120607

McArdle, F., Pattwell, D.M., Vasilaki, A., McArdle, A., \& Jackson, M.J. (2005). Intracellular generation of reactive oxygen species by contracting skeletal muscle cells. Free Radical Biology \& Medicine, 39(5), 651-657. doi:10.1016/j.freeradbiomed.2005.04.010

McGinnis, G., Kliszczewiscz, B., Barberio, M., Ballmann, C., Peters, B., Slivka, D., . . . Quindry, J. (2014). Acute Hypoxia and Exercise-Induced Blood Oxidative Stress. International Journal of Sport Nutrition and Exercise Metabolism. PubMed doi:10.1123/ijsnem.2013-0188

Miller, L.E., McGinnis, G.R., Kliszczewicz, B., Slivka, D., Hailes, W., Cuddy, J., . . . Quindry, J.C. (2013). Blood oxidative-stress markers during a highaltitude trek. International Journal of Sport Nutrition and Exercise Metabolism, 23, 65-72. PubMed doi:10.1123/ijsnem.23.1.65

Møller, P., Loft, S., Lundby, C., \& Olsen, N.V. (2001). Acute hypoxia and hypoxic exercise induce DNA strand breaks and oxidative DNA damage in humans. The FASEB Journal, 15, 1181-1186. PubMed doi:10.1096/fj.00-0703 com

Morales-Alamo, D., Ponce-Gonzalez, J. G., GuadalupeGrau, a., Rodriguez-Garcia, L., Santana, a., Cusso, M. R., ... Calbet, J. a. L. (2012). Increased oxidative stress and anaerobic energy release, but blunted Thr172-AMPK phosphorylation, in response to sprint exercise in severe acute hypoxia in humans. Journal of Applied Physiology, 113, 917 928. doi:10.1152/japplphysiol.00415.2012

$\underline{\text { PubMed }}$

Peters, B., Ballmann, C., McGinnis, G., Epstein, E., Hyatt, H., \& Slivka, D. (2015)... Quindry, J. (2015). Graded hypoxia and blood oxidative stress during exercise recovery. Journal of Sports Sciences, 34(1), 56-66.

Quindry, J., Dumke, C., Slivka, D., \& Ruby, B. (in press).Impact of extreme exercise at high altitude on oxidative stress in humans. The Journal of Physiology, 594(18), 5093-5104. PubMed
Radak, Z., Acs, Z., Bori, Z., Taylor, A. W., \& Yang, H. (2014). The effects of high altitude exposure on reactive oxygen and nitroegn species. Systems Biology of Free Radicals and Anti-Oxidants, 1-10. http://doi.org/10.1007/978-3-319-02904-7

Ristow, M., Birringer, M., Kiehntopf, M., Zarse, K., Oberbach, A., Klo, N., . . . Blu, M. (2009). Antioxidants prevent health-promoting effects. Proceedings of the National Academy of Sciences of the United States of America, 106(21), 88658670. PubMed doi:10.1073/pnas.0903485106

Sanchari, S., Arkadeb, D., Som Nath, S., \& Uday Sankar, R. (2010). Protein nitration, lipid peroxidation and DNA damage at high altitude in acclimatized lowlanders and native highlanders: Relation with oxygen consumption. Respiratory Physiology \& Neurobiology, 171(2), 115-121. PubMed doi:10.1016/j.resp.2010.03.002

Siervo, M., Riley, H. L., Fernandez, B. O., Leckstrom, C. a., Martin, D. S., Mitchell, K., ... Feelisch, M. (2014). Effects of prolonged exposure to hypobaric hypoxia on oxidative stress, inflammation and gluco-insular regulation: The not-so-sweet price for good regulation. PLoS One, 9(4), 1-10. PubMed doi:10.1371/journal.pone.0094915

Sinha, S., Ray, U.S., Saha, M., Singh, S.N., \& Tomar, O.S. (2009). Antioxidant and redox status after maximal aerobic exercise at high altitude in acclimatized lowlanders and native highlanders. European Journal of Applied Physiology, 106(6), 807-814. PubMed doi:10.1007/s00421-0091082-X

Smith, P.K., Krohn, R.I., Hermanson, G.T., Mallia, A.K., Gartner, F.H., \& Provenzano, M.D. ... Klenk, D. C. (1985). Measurement of protein using bicinchoninic acid. Analytical Biochemistry, 150(1), 76-85. Retrieved http://www.ncbi.nlm.nih.gov/pubmed/3843705

Taylor, L., Hillman, A.R., Midgley, A.W., Peart, D.J., Chrismas, B., \& McNaughton, L.R. (2010). Hypoxia-mediated prior induction of monocyteexpressed HSP72 and HSP32 provides protection to the disturbances to redox balance associated with human sub-maximal aerobic exercise. Amino Acids, 43(5), 1933-1944. PubMed doi: $10.1007 / \mathrm{s} 00726-012-1265-3$

Taylor, L., Hillman, A.R., Midgley, A.W., Peart, D.J., Chrismas, B., \& McNaughton, L.R. (2012). Hypoxia-mediated prior induction of monocyteexpressed HSP72 and HSP32 provides protection to the disturbances to redox balance associated with human sub-maximal aerobic exercise. Amino Acids, 43, 1933-1944. PubMed doi: $10.1007 / \mathrm{s} 00726-012-1265-3$

Vij, A.G., Dutta, R., \& Satija, N.K. (2005). Acclimatization to oxidative stress at high altitude. High Altitude Medicine \& Biology, 6(4), 301-310. PubMed doi:10.1089/ham.2005.6.301

Wadley, A.J., Chen, Y.W., Bennett, S.J., Lip, G.Y.H., Turner, J.E., Fisher, J., \& Aldred, S. (2015a). Monitoring changes in thioredoxin and overoxidised peroxiredoxin in response to exercise in 
humans. Free Radical Research, 49(3), 290-298. PubMed doi:10.3109/10715762.2014.1000890

Wadley, A.J., Chen, Y.W., Lip, G.Y., Fisher, J.P., \& Aldred, S. (2015b). Low volume-high intensity interval exercise elicits anti-oxidant and antiinflammatory effects in humans. Journal of Sports Sciences, 27, 1-9. PubMed

Wadley, A.J., Killer, S.C., Svendsen, I.S., \& Gleeson, M. (2015c). The impact of intensified training with a high or moderate carbohydrate feeding strategy on resting and exercise-induced oxidative stress. European Journal of Applied Physiology. PubMed doi:10.1007/s00421-015-3162-4

Wadley, A.J., Turner, J.E., \& Aldred, S. (in press).Factors influencing post-exercise plasma protein carbonyl concentration. Free Radical Research. PubMed

Wilber, R.L., Holm, P.L., Morris, D.M., Dallam, G.M., Subudhi, A.W., Murray, D.M., \& Callan, S.D. (2004). Effect of FIO2 on oxidative stress during interval training at moderate altitude. Medicine and Science in Sports and Exercise, 36(31), 18881894. doi:10.1249/01.MSS.0000145442.25016.DD

Wozniak, A., Drewa, G., Chesy, G., Rakowski, A. Rozwodowska, M., \& Olszewska, D. (2001). Effect of altitude training on the peroxidation and antioxidant enzymes in sportsmen. Medicine and Science in Sports and Exercise, 33(7), 1109-1113. PubMed doi:10.1097/00005768-200107000$\underline{00007}$

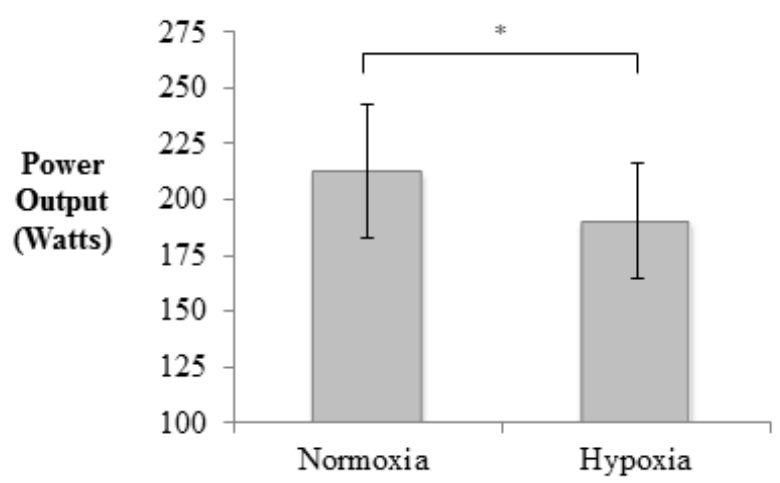

Figure 1 - Average power output during the hypoxic and normoxic conditions. Values are means \pm SD. $* p<.0001$ indicates a significant difference between normoxia and hypoxia trials.
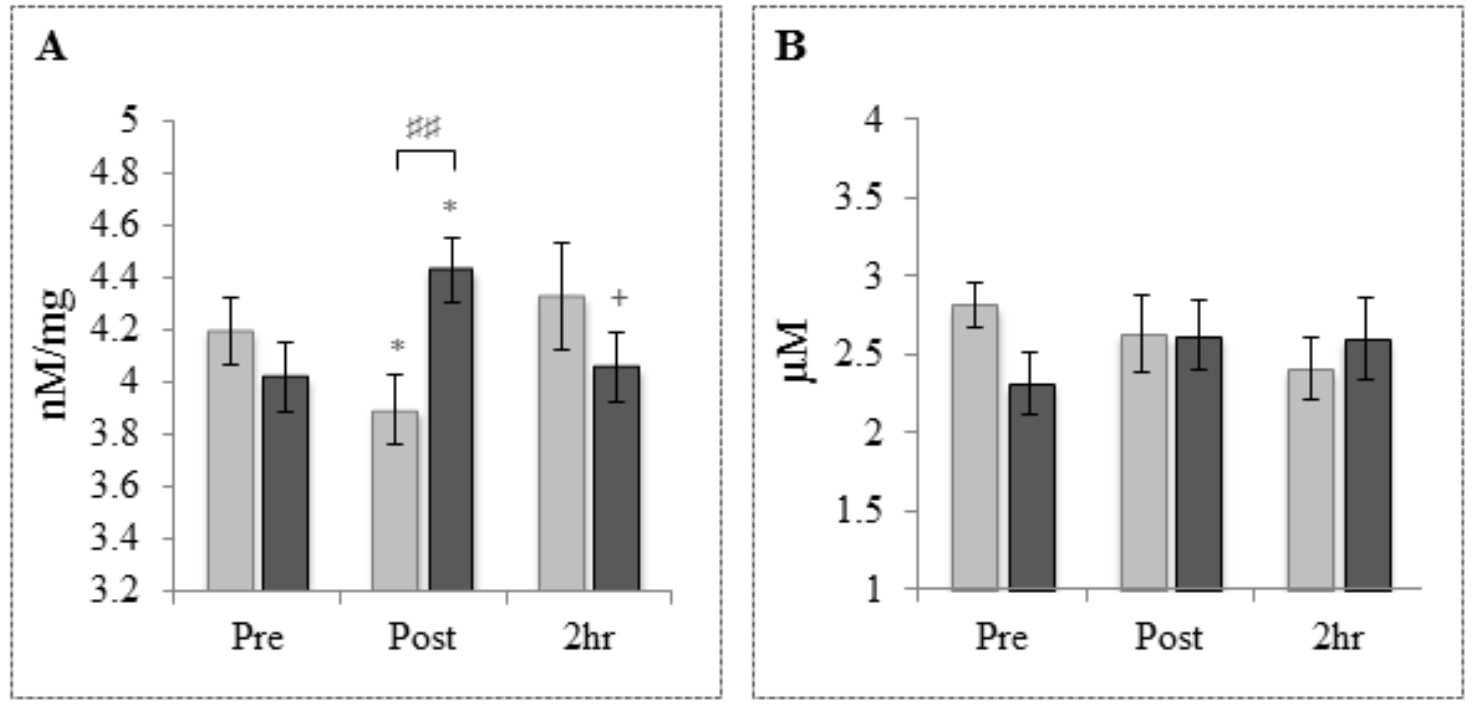

Figure 2 - Oxidative biomarker responses after exercise under hypoxic and normoxic conditions. A) Protein Carbonylation; B) TBARS; Values are means $\pm S E$. A symbol above a dotted line indicates a significant effect of time, whereas a symbol above individual bars represents a significant pairwise comparison from a time*condition interaction effect. * indicates a significant difference POST, relative to PRE: $* p<.05 .{ }^{+}$indicates a significant difference between POST and $2 \mathrm{~h}$ POST $(2 \mathrm{hr}$ in Fig 1$):{ }^{+} p<$ .05. \# indicates a significant difference between hypoxia and normoxia (time*condition interaction effect): ${ }^{\#} p<.001$. 

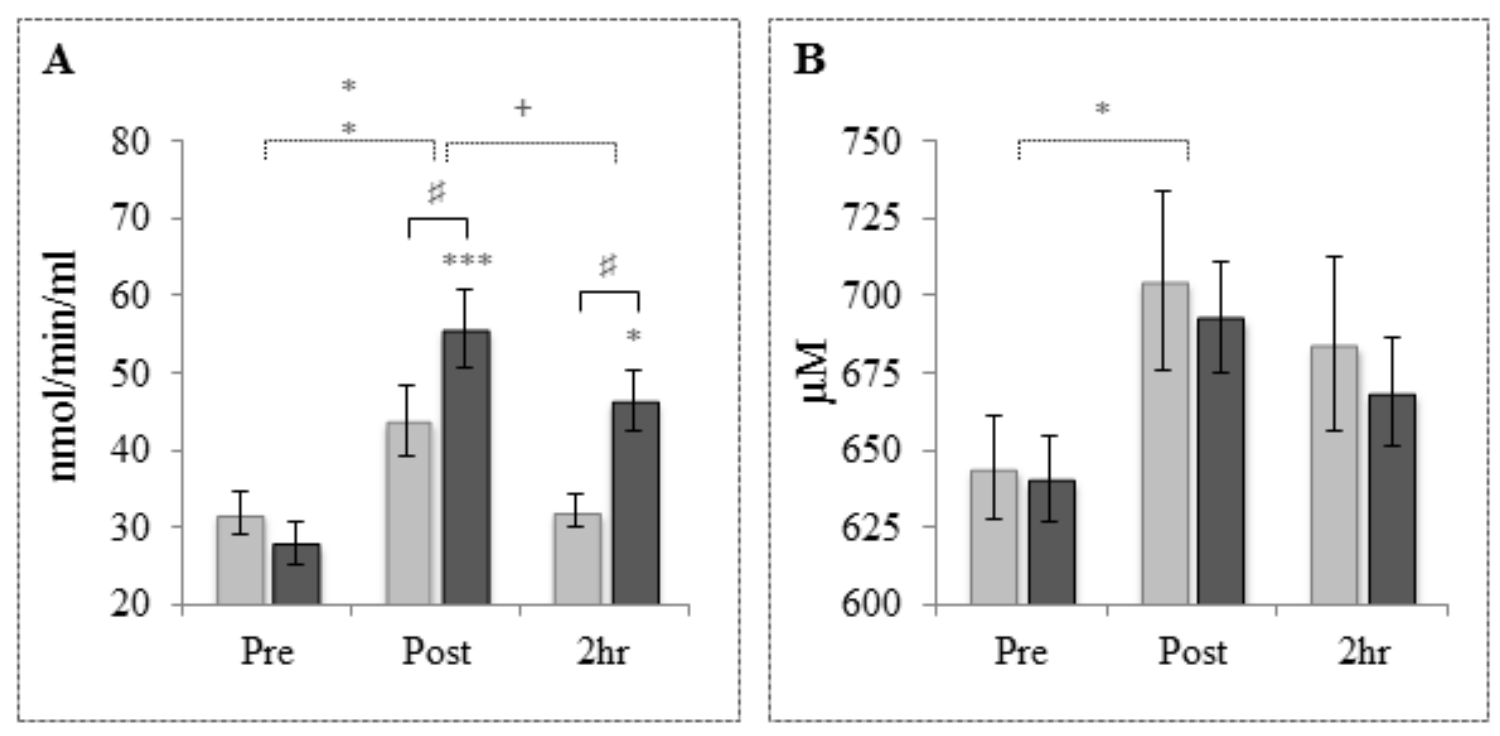

Figure 3 - Antioxidant responses after exercise under hypoxic and normoxic conditions. A) Catalase activity; B) Total Antioxidant Capacity. Values are means $\pm S E$. A symbol above a dotted line indicates a significant effect of time, whereas a symbol above individual bars represents a significant pairwise comparison from a time*condition interaction effect. * indicates a significant difference POST, relative to PRE: $* p<.05, * * p<.001 * * * p<.0001{ }^{*}{ }^{+}$indicates a significant difference between POST and $2 \mathrm{~h}$ POST $(2 \mathrm{hr}$ in Figure 1$):{ }^{+} p<.05 .{ }^{\#}$ indicates a significant difference between hypoxia and normoxia (time* condition interaction effect): ${ }^{\#} p<.05$.

Table 1 Participants Characteristics

\begin{tabular}{lc}
\hline Patient Characteristics & $(N=12)$ \\
\hline Age (years) & $28(4)$ \\
Body mass $(\mathrm{kg})$ & $79.1(5.9)$ \\
$\mathrm{VO}_{2 \mathrm{MAX}}(\mathrm{ml} / \mathrm{kg} / \mathrm{min})$ & $63.7(5.3)$ \\
\hline
\end{tabular}

Note. Values are mean $(S D)$.

Table 2 Average Rating of Perceived Exertion (RPE), Heart Rate, and Lactate Levels During Steady State Exercise Under Hypoxic and Normoxic Conditions

\begin{tabular}{lcc}
\hline [AUQ2] & Normoxia & Hypoxia \\
\hline RPE (6-20) & $15(0.7)$ & $15(0.5)$ \\
Heart Rate $(\mathrm{bpm})$ & $157(11)$ & $156(12)$ \\
Blood Lactate $(\mathrm{mmol} / \mathrm{L})$ & $3.06(1.5)$ & $3.25(1.7)$ \\
\hline
\end{tabular}

Note. Values are mean $\pm S D$. 